\section{Jurnal \\ Teknologi \\ INVENTORY RISK BASED TECHNIQUE FOR SPARE PARTS UTILIZATION}

\author{
Kamal Imran Mohd Sharif*, Jafni Azhan Ibrahim, Zulkifli M Udin \\ School of Technology Management \& Logistics, Universiti \\ Utara Malaysia, 06010 Sintok, Kedah, Malaysia
}

Article history

Received

02 June 2015

Received in revised form

09 June 2015

Accepted

1 September 2015

*Corresponding author: kamalimran@uum.edu.my

\section{Graphical abstract}

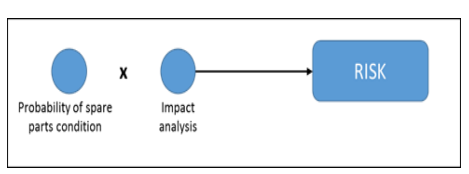

\begin{abstract}
The equipment breakdown due to unavailability of spare parts has incurred challenges for the manufacturing industry in managing the inventory. Consequently, the problem of spare parts unavailability has lead the organization towards unproductive and eventually impact the financial performance. Therefore, maintaining good system has direct connection with spare parts availability. The inventory planner always strive hard to ensure that the spare parts are always available for the maintenance used. Nevertheless, maintaining high inventories of spare parts often conflict from meeting the needs of equipment reliability for the manufacturing plant. In view of this situation, management of spare parts become critical in ensuring the equipment reliability. This paper describes an innovative risk quantification technique using Binary Decision Diagram (BDD) for the spare parts inventory control. The technique modified the BDD concept by translating the failure history into binary decision. From the binary process, the data will be converted into spare parts probability table and failure impact is analyzed. These two functions of risk, will be calculated in order gain the risk in monetary value.
\end{abstract}

Keywords: Inventory management; risk based technique; spare parts; risk quantification; binary decision diagram

\subsection{INTRODUCTION}

Maintenance is an action of sustaining the equipment or restoring it to a given condition [1]. Ultimately the maintenance can be concluded as an activity that keeping the plant operation in working order and maintain the system capability. In United States over the last 3 decades, there were many maintenance approaches developed in order to confirm the equipment extents or exceeds its design life [2]. Based on the situation, Scott [3] stated that, inventory management has the largest impact towards maintenance productivity. Nevertheless, due to improper inventory management, resulting in stunted maintenance process and ultimately led to the issue of company opportunity loss. Inventory management is a crucial aspect of managing a company successfully. Moreover, maintenance and inventory management are the two functions in the company that is interconnected to each other. By having a good maintenance practice also, the company can keep its inventory in order to ensure the maintenance can restore the equipment according to its intended function [4].This is even more apparent in the case of spare parts for maintenance inventories for the use of production lines, which impact directly on production equipment efficiency. Furthermore, one way to achieve high operational readiness is to acquire enough spare parts. Lately, the area of stock control has received much attention from the scientific community for many decades now. The majority of literature is focused on the decision on replenishing the stock in order to supply production lines with spare parts, raw material and stock control for distribution networks. However, the objectives of meeting the high inventories of spare parts often conflicting from the 
needs of stock availability in inventory management [5]. In view of this situation, it is good point to incorporate risk perspective into the decision making processes. Specifically, risk is the combination of the probability of a stock out event and its consequence, where a stock out is an event when a spare is not available on demand.

In recent years, researchers have used qualitative risk analysis as the basis for the analysis of probabilities and consequences. The analysis used can be performed from two perspective which are best estimates from experts as well as raw historical data. For instance some of the technique used are Failure Modes, Effects, Criticality Analysis (FMECA) and Hazard and Operability Studies (HAZOPs). These techniques become quantitative when consequences and failure probability values are estimated in numerical terms. Quantitative risk analysis usually involves a) identifying the combinations of events that, if they occur lead to an undesired event, b) calculating the frequency of occurrence for each combination, and c) calculating the consequences. In this situation, a risk profile of the spares is obtained by considering the likelihood of a failure to meet the demand for a spare in conjunction with the consequences of the failure to meet that demand. This risk profile is then used to find the optimal level of inventory such that financial benefit is maximized given an identified acceptable risk level.

Moreover, the Risk Based Maintenance (RBM) encompassed of two main segments that are maintenance planning and risk assessment where it reduce the risk from the unexpected failure happen in the operation premises [6]. The risk based maintenance activity indirectly reduce the total risk, as the maintenance activities are prioritize based on risk and being quantified [7]. On the other hand, the spare part with high-risk category will be inspected frequently in order to avoid the potential failure and achieving appropriate risk toleration [8]. In addition, assessing risk is crucial because the decision to maintain equipment can affect cost [7]. Quantified risk assessment is only relevant if the given data is enough to identify the value of the risk as compared to the problem solving [9]. Khan and Haddara [6] used the risk matrix to define the risk and consequences. Besides that, Balemans [10] developed spare part checklist for chemical industry. Respectively, Rogers [11] used the check list for listing the possible risk that is related to plant hazard in operation. However, a checklist only served as a guidelines for the maintenance to identify the potential failure of spare part for every stage. Furthermore a Fault Tree Analysis can be used to examine risks occurred based on the events and logic that links the issues in order [11]. Pumfrey [12] also described HAZOP as a technique to predict the operating problems that is related to spare parts requirement in operation. The stated technique will provide the study on cause and effect of spare parts in the plant and the comparative used from one to another. Nevertheless, inventory management decisions are a complex case. Too much money ties in inventory burdens the manufacturer with the high costs of inventory service and additionally high alternative costs [13]. While, too little inventory can result in production delays and lost in sales.

This paper will focus on the development of risk based technique for spare parts utilization in manufacturing industries. Nevertheless, questions have been raised on how to determine the optimal size of the inventory based on the risks inherent in the equipment. In view of that, there is growing concern to address the issue of inventory based on the potential risks posed by the plant. The research presents a technique for designing the level of spare parts quantity by looking at the likelihood of inventory risk towards the maintenance performance. Initially, the data was collected based on the spare parts failure history of the organization and the spare parts failure frequency was expressed using the Binary Decision Diagram technique. The technique contributes as principle guidelines for the maintenance planner to plan their inventory spare parts for maintenance activity. In order to achieve this, the technique quantified the risk into monetary value which at the end of the day the maintenance planner would be able to make a better decision in identifying the optimum quantity of the spare parts and minimize the inventory cost.

\subsection{RISK QUANTIFICATION TECHNIQUE}

In order to models the complexity of the spare parts reliability in which the causes of equipment failure, it can be expressed using the binary codes. Lee [14] was the first one to introduce a new representation for switching circuits which would come to be known as Binary Decision Diagram (BDD). With some modification of BDD concept and research in the areas of interest, it is believed that valuable contribution can be made into the interest areas especially areas that concerning with machinery spare parts and risks. There were 2 units of equipment's that were tested using this particular technique which are the natural gas(NG) and sync gas(SG) compressors. Each unit of equipment is made of spare parts and components combined in assemblies that work together to allow it to operate. The spare parts were the bearing $(\mathrm{Br})$ and dry gas seal (DGS). Both spare parts have major implication towards the plant operation that will cause a total plant shutdown and company losses in the case of spare parts failure. In this study the functions of the spare parts in the operation are considered in two states which are

fail $(f=1)$ and not fail $(\bar{f}=0)$. The $f$ indicated that the spare part had experienced the malfunction that effect the main equipment which is the compressors. While the $f=0$ was state as not fail and defined as the spare part has no experience of failure during the operation of the spare parts. . In this case, as the NG compressor has two spare parts which are the DGS and $\mathrm{Br}$, and the combinations of the compressor condition is expressed as $00,01,10$ and 11 . It goes the same with SG compressor which has the same compressor condition which is $00,01,10$ and 11 . In specific, the combinations 
of the spare part condition in both compressors can be represented in Boolean Operations [15]. The combination using Boolean notation will further lead to better understanding the connection between the two spare parts in the different compressors. Below is the notation of both spare part in Boolean Operations.

$$
\bigcup(A \bigcup B)=\min \{\bigcup(A), \bigcup(B)\}
$$

Where:

$$
\begin{aligned}
& \bigcup(A)=[0,0,0,0] \\
& \bigcup(B)=[0,0,0,0] \\
& A=N G \text { Compressor } \\
& B=S G \text { Compressor }
\end{aligned}
$$

Table 1 The $\bar{f}$ and $f$ combinations for DGS and $\mathrm{Br}$

\begin{tabular}{llll}
\hline \multicolumn{2}{l}{ NG Compressor } & \multicolumn{2}{l}{ SG Compressor } \\
\hline DGS & $\mathrm{Br}$ & DGS & $\mathrm{Br}$ \\
\hline 0 & 0 & 0 & 0 \\
\hline 0 & 1 & 0 & 0 \\
\hline 1 & 0 & 0 & 0 \\
\hline 1 & 1 & 0 & 0 \\
\hline 0 & 0 & 1 & 0 \\
\hline 0 & 0 & 0 & 1 \\
\hline 0 & 0 & 1 & 1 \\
\hline 1 & 1 & 1 & 1 \\
\hline
\end{tabular}

The plant operation cycle for this study begin from January until December of the year and the operation planning divided into four quarters, Qi, $1 \leq i \leq 4$. . Thus the presentation of the spare condition for the possible repeated event on quarterly basis in BDD concept is presented as below:

$$
\sum f Q i=\bigcup Q i, \text { for } 1 \leq i \leq 4
$$

Where:

$$
Q i=\bigcup(A j \bigcup B j), \text { for } 1 \leq j \leq i
$$

The evolution of the possible $f Q i$ is calculated from Q1 until Q4. In particular the evolution means that there is a possibility of the $f Q i$ repeating the same failure and at the same time the $f Q i$ will having different possibilities in other quarter.

Table 2 The spare part possibilities in quarterly basis

\begin{tabular}{ll}
\hline Quarter & fQi Possibilities \\
\hline Q1 & {$[0000]$} \\
\hline Q2 & {$[00000001]$} \\
\hline Q3 & {$[000000010011]$} \\
\hline Q4 & {$[0000000100110111]$}
\end{tabular}

Based on the above composition of the possible $f Q i$ in every quarter, it determined that the overall $f Q i$ in which considering the Qi, $1 \leq i \leq 4$ can be displayed as $\sum f Q i=[0000000000000000,0000000000000001,0000000000000011 \ldots]$. There are 65,356 combinations of $f Q_{i}$ in which coming from the combinations $f Q$ i of DGS and $\mathrm{Br}$.

\subsection{Spare Parts Failure Probability Table}

The critical maintenance analysis discloses that the probable failure of the spare parts availability would have a significant impact on the plant operation to run effectively. Historical data of the $\mathrm{Br}$ and DGS demand and replacement activity were collected from the year 2004 until 2013. The fQi for DGS and $\mathrm{Br}$ is used to calculate probability value of the spare parts.

$\operatorname{Pr}(D G S \bigcup B r)=\sum_{i=1}^{10}($ hourfail $) i / \sum_{i=10}^{10}($ houroperation $) i$

Where:

$\mathrm{Pr}=$ Probability value for $\mathrm{DGS}$ and $\mathrm{Br}$

Based on the failure history in hours for DGS and $\mathrm{Br}$, the probability value is derived from the $\sum f Q i$. As a result, below is the probability $(\operatorname{Pr})$ of failure $D G S$ and $\mathrm{Br}$ from both compressors.

Table 3 Probability (Pr) of DGS and Br from both compressors

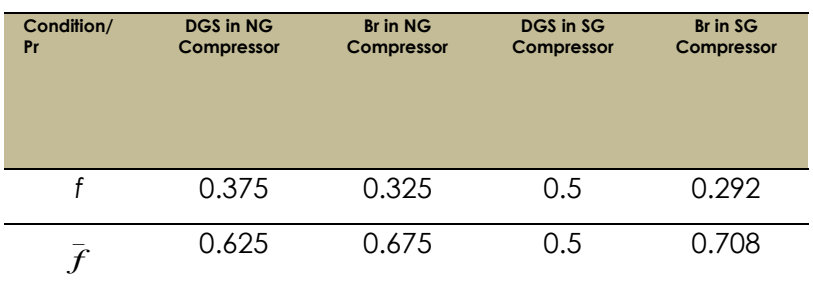

The value of $f Q i$ will be used to find the $\operatorname{Pr}\left(f \bigcup^{-}\right)$for DGS and $\mathrm{Br}$ in both compressors of NG and SG. For instance, the DGS and $\mathrm{Br}$ for both compressors are fail in quarter 1. Supposedly the value $f Q_{1}$ should be 1111 in which representing the $f$ value for all the spare parts. In this scenario the value $f Q_{1}$ which is 1111 the value of $\operatorname{Pr}(f \bigcup \bar{f})$ is equivalent to $(0.375 \times 0.325 \times 0.5 \times 0.292)$. The likelihood of this failure occurring is equivalent to probability of 0.0188 . The $f Q_{1}$ combination of possibilities in $Q 1$ is 16 or $2^{4}$. This indicated that there are 16 possibilities of $f Q_{1}$ that can be predicted from the quarter 1 spare parts history. The table below illustrates the $f Q_{1}$ combinations for 16 possibilities in quarter 1 . 
Table $4 \mathrm{fQ}$, combinations of possibilities in quarter 1 .

\begin{tabular}{ccc}
\hline $\begin{array}{c}\text { Possible } \\
\text { Combinations } \\
\text { Quarter 1 }\left(f Q_{1}\right)\end{array}$ & $\begin{array}{c}\text { Probability Derivations } \\
\operatorname{Pr}(f \cup \bar{f})\end{array}$ & $\begin{array}{c}\text { Probability } \\
\text { Value }\end{array}$ \\
\hline 1111 & $(0.375 \times 0.325 \times 0.5 \times 0.292)$ & 0.017994 \\
\hline 1010 & $(0.375 \times 0.675 \times 0.5 \times 0.708)$ & 0.089606 \\
\hline 0001 & $(0.625 \times 0.675 \times 0.5 \times 0.708)$ & 0.149344 \\
\hline 0110 & $(0.625 \times 0.325 \times 0.5 \times 0.708)$ & 0.071906 \\
\hline 0101 & $(0.625 \times 0.325 \times 0.5 \times 0.292)$ & 0.029656 \\
\hline 1110 & $(0.375 \times 0.325 \times 0.5 \times 0.708)$ & 0.043143 \\
\hline 1001 & $(0.375 \times 0675 \times 0.5 \times 0.292)$ & 0.036956 \\
\hline 0111 & $(0.625 \times 0.325 \times 0.5 \times 0.292)$ & 0.029656 \\
\hline 0011 & $(0.625 \times 0.675 \times 0.5 \times 0.292)$ & 0.061594 \\
\hline 0100 & $(0.625 \times 0.325 \times 0.5 \times 0.708)$ & 0.071906 \\
\hline 1100 & $(0.375 \times 0.325 \times 0.5 \times 0.708)$ & 0.043144 \\
\hline 1101 & $(0.375 \times 0.325 \times 0.5 \times 0.292)$ & 0.017794 \\
\hline 0010 & $(0.625 \times 0.675 \times 0.5 \times 0.708)$ & 0.149344 \\
\hline 1011 & $(0.375 \times 0.675 \times 0.5 \times 0.292)$ & 0.036956 \\
\hline 1000 & $(0.375 \times 0.675 \times 0.5 \times 0.708)$ & 0.089606 \\
\hline 0000 & $(0.625 \times 0.675 \times 0.5 \times 0.708)$ & 0.149344 \\
\hline
\end{tabular}

The process of getting the $\operatorname{Pr}(f \bigcup f)$ value is continued in $Q_{2}, Q_{3}$ and $Q_{4}$. For example, in $f Q_{2}$ is the derivation from the $Q i=\bigcup(A j \bigcup B j)$, for $1 \leq j \leq i$ will determine specific $f Q_{2}$ possibilities. For example, in $Q_{1}$ both compressors, the NG and SG were experiencing malfunction for DGS and $\mathrm{Br}$. Nevertheless, in $\mathrm{Q}_{2}$ only DGS and Br in SG Compressor are having the problem. In this scenario, the $f Q_{2}$ should be expressed as 11110011 . The possibilities for the $Q_{2}$ are increasing by the value of $f Q_{2}$. In particular the $f Q_{2}$ of 11110011 will represented in probability value in order to get $\operatorname{Pr}(f \bigcup \bar{f})$. In this scenario, the $\operatorname{Pr}(f \bigcup \bar{f})$ for 11110011 $(0.375 \times 0.325 \times 0.5 \times 0.292 \times 0.625 \times 0.675 \times 0.5 \times 0.708)$. For this scenario, the value for $\operatorname{Pr}(f \bigcup f)$ in $Q_{2}$ is 0.001095984 . The $f Q_{2}$ possibilities is increasing as it combined value from $Q_{1}$. The total combinations for $Q_{2}$ is 256 or $2^{8}$.

\subsection{Determination of Failure Impact Value}

The value of risk is subjected to the following assumptions: spare parts condition probability value and impact of the spare parts unavailability. The failure of the spare parts which are DGS or Br to perform their function may result the NG or SG compressor malfunction and consequently it will cause the plant to stop operation. In view of this scenario, below is the list of 7 possible impact for the DGS and $\mathrm{Br}$ in compressor NG and SG:

a. Criteria 1: Value Impact of NG Compressor with DGS and Br Malfunction

b. Criteria 2:Value Impact of NG Compressor with only DGS Malfunction

C. Criteria 3: Value Impact of NG Compressor with only Br Malfunction

d. Criteria 4: Value Impact of SG Compressor with DGS and Br Malfunction

e. Criteria 5: Value Impact of SG Compressor with DGS Malfunction f. Criteria 6: Value Impact of SG Compressor with Br Malfunction

g. Criteria 7: Value Impact of NG Compressor and SG Comp Malfunction

The NG compressor is considered the most critical equipment in the plant operation. For this reason, the failure of the NG comp will cause a total shutdown of the plant. In addition, the maintenance work in order to fix the spare part will take about 10 days until it can bring the compressor back to the normal condition. In particular, the explanation about the impact scenario can be illustrated based on example below:

Table 5 Example of impact scenario

\begin{tabular}{ccccc}
\hline \multicolumn{5}{c}{ Compressor } \\
\hline \multirow{2}{*}{ NG } & \multicolumn{3}{c}{ SG } \\
\hline DGS & $\mathrm{Br}$ & DGS & $\mathrm{Br}$ \\
\hline 1 & 1 & 0 & 0
\end{tabular}

The above table explained that the NG compressor experiences malfunction due to DGS and $\mathrm{Br}$ is not working at similar time. Therefore, these spare parts need to be replaced and required a maintenance work for about 10 days as the plant need to be a total shutdown. On the other hand, the SG compressor does not experience any issue of DGS and $\mathrm{Br}$ malfunction and the compressor can be operated in normal condition. The formulation for the impact is stated as below:

$$
\text { INGC }(D G S \bigcup B r)=C t I
$$

Where:

$C=$ condition of shutdown $=100 \%$

$t$ = number of shutdown days $=10$

$I=$ total impact value $=$ RM2, $688,000.00$

Therefore, there are two perspective in determining the impact value in order to obtain the spare parts requirement which are the condition of the plant and the spare parts. Both of this perspective will give a significant impact to the process of determining the impact value for the risk calculation.

\subsection{The Risk Calculation}

In an attempt to minimize or avoid such losses, the second level of this research is done by quantifying the risk into monetary value. This formulation is developed by multiplying the probability combinations of the spare parts condition with the possible impact condition of the spare parts in the respective equipment. Particularly the level of risk in inventory requirement will depend on the prediction of the spare parts condition and impact analysis of the compressors. On the other hand, the quantity of spare parts used for the compressors which referring to DGS and $\mathrm{Br}$ are considered as the frequency of spare part restoration to the respective compressors. 
The restoration of the spare parts can be defined from the combination pattern of the possible condition of the spare part in the compressors. For this reason the process of identifying the spare parts quantity will provide the value of inventory cost for the respective spare parts. The framework for the risk quantification and inventory cost determination is showed as below:

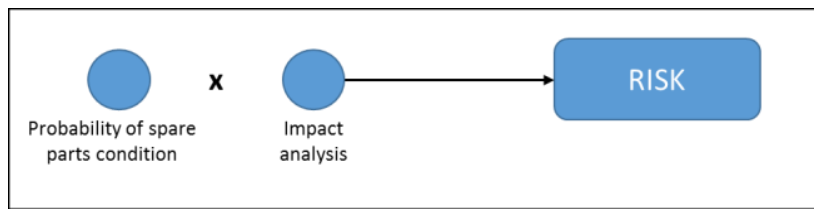

Figure 1 Framework of risk based technique for spare parts inventory level

The framework showed on how the decision of determining the spare parts requirement incorporated with the risk value. The risk will be quantified into monetary value in facilitating the inventory planner making a good judgment in terms of the spare parts requirement. For the risk formulation, there are two parameters that need to be considered, the probability of the spare parts condition and impact analysis. The calculation of the probability of the spare part will lead to the calculation of possible impact value of the spare parts condition. Next, the probability $(P)$ value of the identified spare parts will be multiplied with the value of possible impact (I) in order to get the risk value. The risk value will be in high state or lower state as it depend on the probability value and impact criteria of the spare part. Below is the risk calculation for the spare parts requirement:

$$
R_{s p}=P_{s p} \times I_{s p}
$$

Where:

$$
\begin{aligned}
& R=\text { Spare Part risk } \\
& P=\text { Probability of spare part condition } \\
& I=\text { Impact }
\end{aligned}
$$

Subsequently, the value of the risk for each spare parts are different according to the possible condition and impact scenario. In particular, the possibility of the spare parts failure will be determined according to the condition of the spare parts from one quarter to another quarter. Likewise, the value of the risk also will be affected based on the criteria of the impact from each of the spare parts. The example below demonstrate the risk value from each quarter based on the failure combination for the two spare parts.

$$
R_{Q i}=P(f Q i) x I_{s p}
$$

where :

$$
P\left(f Q_{i}\right)=D G S_{Q i} \bigcup B r_{Q i} \text { for } 1 \leq i \leq 4
$$

Table 6 Example of value of risk for $Q_{1}$.

\begin{tabular}{cccc}
\hline $\begin{array}{c}\text { Possible } \\
\text { Combinations } \\
\text { Quarter 1 }\left(f Q_{1}\right)\end{array}$ & $\begin{array}{c}\text { Probability } \\
\text { Value }\end{array}$ & Impact (RM) & Risk (RM) \\
\hline 1111 & 0.017994 & $26,880,000.00$ & $483,678.72$ \\
\hline 1100 & 0.043144 & $26,880,000.00$ & $1,159,710.72$ \\
\hline 0011 & 0.061594 & $21,504,000.00$ & $1,324,517.38$ \\
\hline 0001 & 0.149344 & $10,752,000.00$ & $1,605,746.68$ \\
\hline
\end{tabular}

The first stage of the model deliberated the risk value by using two parameters which are the probability and quantified impact value. This two parameters will be multiplied in order to get the risk value. However, before the calculation for the risk is carried out, the process started with synthesizing possible combinations from the spare parts failure history and segregate the combinations in quarterly basis. Then, the second part is analyzing the impact of the spare parts based on the plant operation condition.

\subsection{CONCLUSIONS}

This paper presents a technique in determining spare parts quantity by quantifying the risk into monetary value. The level of the spare parts requirement is designed by looking at the likelihood of inventory risk towards the maintenance performance. The risk was quantified into monetary value in order to facilitate the inventory planner making a good judgment in terms of the spare parts requirement. The technique contributes as principle guidelines for the maintenance planner to plan their inventory spare parts for maintenance activity. Thus it will ensure that the dependability of equipment is increased and the cost of inventory will be minimized. Indirectly, the technique will contribute to the performance of the plant operation. On the other hand the methodology used can also be extended in other areas that dealing with risk management such as financial, insurance, property management where challenging risks of failure need to be managed within limited resources.

\section{Acknowledgement}

The authors would like to extend a deepest appreciation to the supervisor, Dr Jafni Azhan Ibrahim and Associate Professor Dr. Zulkifli Mohamed Udin from School of Technology Management and Logistics, Universiti Utara Malaysia, for their truly expert advice, continuous support and encouragement during the research progress. 


\section{References}

[1] Dhillion, B. (2002). Engineering Maintenance, A Modern Approach. New York: CRC Press.

[2] Sullivan, G. P., Pugh, R., Melendez, A. P., \& Hun, W. (2010). Operations \& Maintenance. Federal Energy Management Program.

[3] Scott, S., \& Consultant, S. (2004). Annual International Supply Management Conference, April 2004, (April), 1-3.

[4] Van Horenbeek, A., Buré, J., Cattrysse, D., Pintelon, L., Vansteenwegen, P. (2013). Joint Maintenance And Inventory Optimization Systems: A Review. International Journal of Production Economics, 143(2), 499-508. doi:10.1016/j.ijpe.2012.04.001

[5] Ibrahim, J. A., Kamal, I. M. S., Udin, Z. M., \& Hasni, N. (2015). Risk Based Prediction Technique on Critical Spare Parts Requirement for Plant Producer. Journal of Engineering and Applied Sciences. 10(3), 1338-1344.

[6] Khan, F. I., \& Haddara, I. (2004). Risk-Based Maintenance (RBM): A New Approach For Process Plant Inspection And Maintenance. Process Safe, 252-265.

[7] Arunraj, N. S., \& Maiti, J. (2007). Risk-Based MaintenanceTechnique Sand Applications. Journal of Hazardous Materials, 653-661.
[8] Brown, S. J., \& May, I. J. (2003). Risk-Based Hazardous Protection and Prevention By Inspection And Maintenance. J.Press. Ves.Technology, 362-367.

[9] Carter, D. A., Hirst, I. L., Maddison, T. E., \& Porter, S. R. (2003).Appropriate Risk Assessment Methods For Major Accident Establishments. Process System Risk Management. 12-18.

[10] Balemans. (1974). Check-list Guide Line for Safe Design of Process Plant. First international Loss Prevention Symposium, 7-33.

[11] Rogers, R.L. (2000). The RASE Project Risk Assessment Of Unit Operations and Equipment, http://www.safetynet.de/ECProjects/. Pp.1-50.

[12] Pumfrey, D. J. (1999). The Principled Design of Computer System Safety Analysis. 11-219.

[13] Wall K. D (2011) The Kaplan and Garrick Definition of Riskand its Application to Managerial Decision Problems: DRMI, Naval Postgraduate School.

[14] C.Y. Lee. (1959) Representation Of Switching Circuits By Binary Diagrams. Bell System Technical Journal, 38:985-999.

[15] Zadeh, L. (1965) Fuzzy sets, Information and Control, 8, 338 353. 